\title{
Cystatin-C as Novel Marker of Neonatal Hyperbilirubinemia, IN Al-Najaf City, Iraq
}

\author{
Sarah Ali Aljazaeri ${ }^{1 *}$ \\ ${ }^{1}$ Medical Laboratory Techniques, Altoosi University College, Najaf, Iraq. \\ **e-mail: sarah.a.nasser@altoosi.edu.iq
}

ABSTRACT

Neonatal hyperbilirubinemia results from a readiness for the bilirubin production in neonates and limited their ability to excrete it. The diagnosis of hyperbilirubinemia based on yellow discoloration of the skin and whiteness of eyes, idle in the child's movement and the lack of lactation. The baby seems sick or is difficult to awaken. Serum cystatin-C, is a low molecular protein that belongs to the family of cysteine protease inhibitor, was proposed as an endogenous filtration marker. In this study sixty neonatal patients suffering from hyperbilirubinemia (35 males, 25female) were collected from prematurity unit (PU) in Al-Zahra Educational Hospital/Al-Najaf Al-Ashraf during the period from August,2020 to February,2021. A group of 20 randomly (12male, 8female) selected apparently healthy group. After diagnosis of hyperbilirubinemia, the patients were divided into three groups according to age (1-3), (4-7) and (7-9) days. The result reveals that significant increase $(p<0.05)$ in serum cystatin-C in neonatal hyperbilirubinemia as compared with healthy group. The result of study reveals no significant increase $(p<0.05)$ in serum levels of cystatin-C, while the study shows a significant increase $(p<0.05)$ between male and female in serum levels of bilirubin.

Keywords: Hyperbilirubinemia, TSB, cystatin-C

Article Information

Received: May 8, 2021; Revised: May 26, 2021; Online: June 30, 2021

\section{INTRODUCTION}

Neonatal jaundice It is the common condition of medical importance in newborns, also called Neonatal jaundice or Neonatal icterus, in which the yellow pigment bilirubin can accumulate in the extracellular fluids by the way in the skin, over the sclera in the membranes of conjunctival and in other membranes of mucous after birth within the first few days, as well as skin prevails in yellow almost in face and extending down onto the chest, jaundice of neonate in normal circumstances is harmless: this condition is often seen in infants around the second day after birth, and goes on till day 8 in normal births, or to about day 14 in premature births. Common reasons of neonatal jaundice include jaundice due to formula supplementation, normal physiologic and hemolytic jaundice that include deficiency of glucose-6-phosphate dehydrogenase ,hereditary spherocytosis (Kaplan and Hammerman,2002; Watchko and Maisels,2003), deficiency of pyruvate kinase, autoantibodies of $\mathrm{ABO} / \mathrm{Rh}$ blood type, or infantile pyknocytosis (Huang et al.,2013).

Neonatal hyperbilirubinaemia could happen by $2 / 3$ of all healthy newborns (NIHCE ,2010), it is the most common cause of readmission after discharge from birth hospitalization in spite of that jaundice is physiologically normal and for aim of preventing risk of elevated hyperbilirubinaemia and bilirubin encephalopathy necessary to diagnose the real reasons of jaundice(YICSSG ,2008; Woodgate and Jardine ,2011). 
Cystatin-C used as an alternative biomarker to evaluation of kidney function is linked with cardiovascular disease and mortality than serum creatinine that used traditionally (Chen et al.,1997; Shlipak et al.,2005; Astor et al., 2009). A protein low molecular weight that inhibitor of cysteine protease as an extracellular (Grubb, 2000; Maria et al.,2008), formerly post-gammaglobulin, gamma trace or polypeptide of neuroendocrine basic (Filler et al.,2004).

It is non glycated protein contains about 122 amino acids, it is a member of cystein proteinase inhibitors family (Christine et al.,2010). It is the house keeping product of gene in all nucleated cells, whereas, is produced at fixed rate (Abrahamson et al.,1990; Qiang et al.,2010). This protein discovered for the first time of healthy patients in the cerebrospinal fluid, also in the urine of patients with tubular diseases then later detected in the dialysis patient's serum (Charlton et al., 2013).

\section{MATERIALS AND METHODS}

Samples The study was conducted on sixty neonates hyperbilirubinemia patients (25female, 35male), suffering from severe jaundice (TSB $\geq 15 \mathrm{mg} / \mathrm{dl}$ ). The patient's age was ranging from 1 to 9 days The study was carried out from August, 2020 to February, 2021, samples were collected from the prematurity unit(PU)in Al-Zahra Educational Hospital/AlNajaf Al-Ashraf. Hyperbilirubinemia was diagnosed by Pediatricians. The information of patients was obtained through data that included the name, gender, age. The diagnosis of neonatal jaundice based on visual examining of newborn that include the yellow discoloration of skin and white of eyes, as well as testing blood levels of bilirubin. A blood test involves collecting a small amount of blood, this test is available in most hospitals. TSB level was measured immediately after drawing blood.

Blood collection Blood samples 3 milliliter were drawn by trained nurses or laboratory analysts. Blood was left at room temperature for 10 minutes for clotting, centrifuged $6000 \mathrm{rpm}$ for 10 minutes, and then serum was separated and freezing at $-20^{\circ} \mathrm{C}$.

Serum Cystatin-C This assessment employs a quantitative sandwich enzyme immunoassay technique, and performed by Automated microtiter plate ELISA reader (biokit EL $\times 800$ reader, El $\times 50$ washer, Barcelona / Spain).

Statically analysis The data were analyzed by using windows software packages Graphpad prism v6, data were offered as the mean \pm standard error (SE). Statistical analysis of comparison between the patients and healthy groups were tested by one-way ANOVA test, while the comparison between subgroups was analyzed by t-test. It carried out the correlation between the parameter's correlation coefficient of Pearson. A level of statistically significant determination by $\mathrm{P}$-value $<0.05$.

\section{RESULTS}

Comparison among different age groups of neonatal hyperbilirubinemia.

Result of table (1) showed bilirubin, cystatin-C serum levels of neonatal hyperbilirubinemia to three neonatal ages (1-3) (4-6) (7-9) days. The results observed significant differences $(\mathrm{p}<0.05)$ in serum level of bilirubin at age (1-3) days (14.205 \pm 0.368 $\mathrm{mg} / \mathrm{dl})$ as compared with (4-6) days (17.19 $\pm 0.177 \mathrm{mg} / \mathrm{dl})$ and (7-9) days $(20.49 \pm 0.364 \mathrm{mg} / \mathrm{dl})$. While, the result of Cys-C serum level detected significant difference $(\mathrm{p}<0.05)$ in age $(1-3)$ days $(18.206 \pm$ $0.31 \mathrm{ng} / \mathrm{ml}$ ) as compared with age (4-6) days $(21.587 \pm 0.163 \mathrm{ng} / \mathrm{ml})$ and age (7-9) days $(26.005 \pm 0.437 \mathrm{ng} / \mathrm{ml})$.

\section{Comparison of Cystatin-C between neonatal hyperbilirubinemia patients (male, female) and control group.}

The result of serum Cys-C concentration scored significant increase $(p<0.05)$ in neonatal hyperbilirubinemia $(21.932 \pm 0.458 \mathrm{ng} / \mathrm{ml})$ when compared with HT group $(5.36 \pm 0.564 \mathrm{ng} / \mathrm{ml})$ in figure (1). Also the result in figure (2) showed significant elevated $(\mathrm{p}<0.05)$ in Cys-C of male $(21.887 \pm 0.624 \mathrm{ng} / \mathrm{ml})$ when comparison with HT male $(5.121 \pm 48600 \mathrm{ng} / \mathrm{ml})$, and expressed significant increase $(\mathrm{p}<0.05)$ in Cys-C of female $(21.996 \pm 0.683 \mathrm{ng} / \mathrm{ml})$ as compared with HT female $(4.854 \pm 48422 \mathrm{ng} / \mathrm{ml})$. 


\begin{tabular}{|c|c|c|c|}
\hline \multirow{2}{*}{ Clinical setting } & \multicolumn{3}{|c|}{$\begin{array}{c}\text { Neonatal jaundice } \\
\text { Means } \pm \text { S. E }\end{array}$} \\
\cline { 2 - 4 } & $(1-3)$ Days & $(4-6)$ Days & (7-9) Days \\
\hline Bilirubin(mg/dl) & $* 14.205 \pm 0.368$ & $* * 17.19 \pm 0.177$ & $\mathbf{2 0 . 4 9} \pm 0.364$ \\
\hline P value & $\mathbf{0 . 0 1 1}$ & $\mathbf{0 . 0 9 2}$ & $\mathbf{0 . 0 4 1}$ \\
\hline Cystatin-C (ng/ml) & $\mathbf{1 8 . 2 0 6} \pm \mathbf{0 . 3 1}$ & $* * 21.587 \pm 0.163$ & $* 26.005 \pm 0.437$ \\
\hline P value & $\mathbf{0 . 0 3 3}$ & $\mathbf{0 . 0 2 1}$ & $\mathbf{0 . 0 2 6}$ \\
\hline
\end{tabular}

*Statistically significant differences $(\mathrm{p}<0.05)$ between (1-3) days, (4-6) days and (7-9) days.

$* *$ Statistically significant differences $(\mathrm{p}<0.05)$ between $(4-6)$ days, $(7-9)$ days.

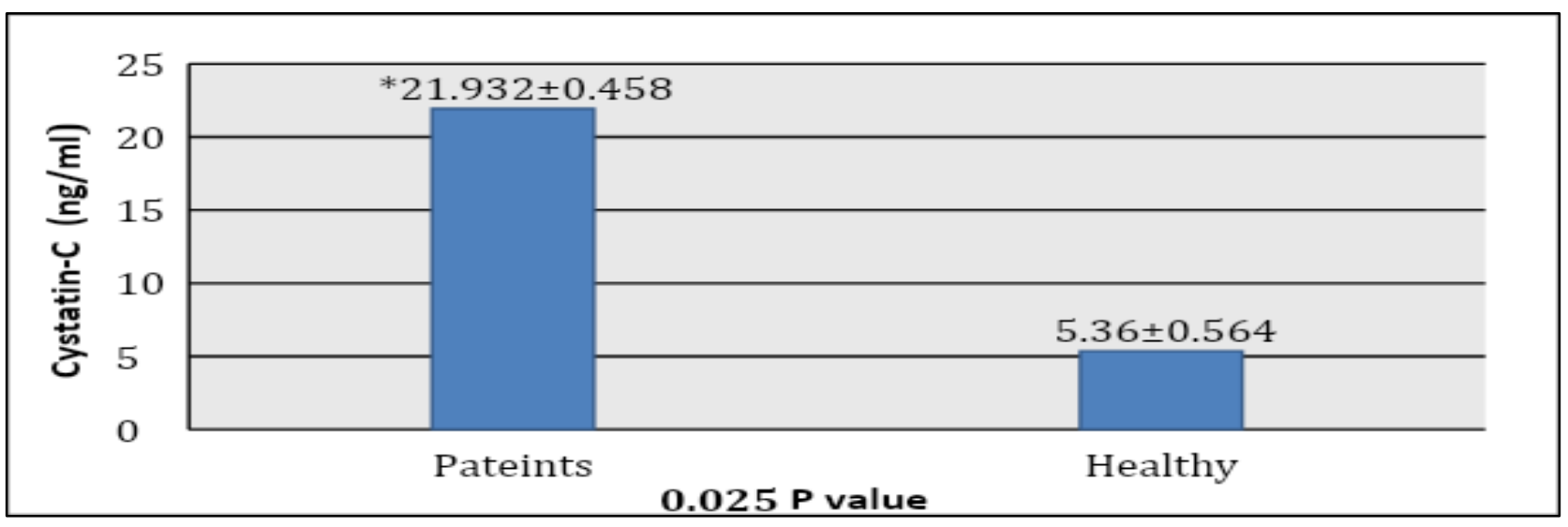

*Statistically significant differences $(\mathrm{P}<0.05)$ of patients and healthy group.

Figure (1): serum level of Cystatin-C in neonatal hyperbilirubinemia patients in comparison with healthy neonatal (HT) group.

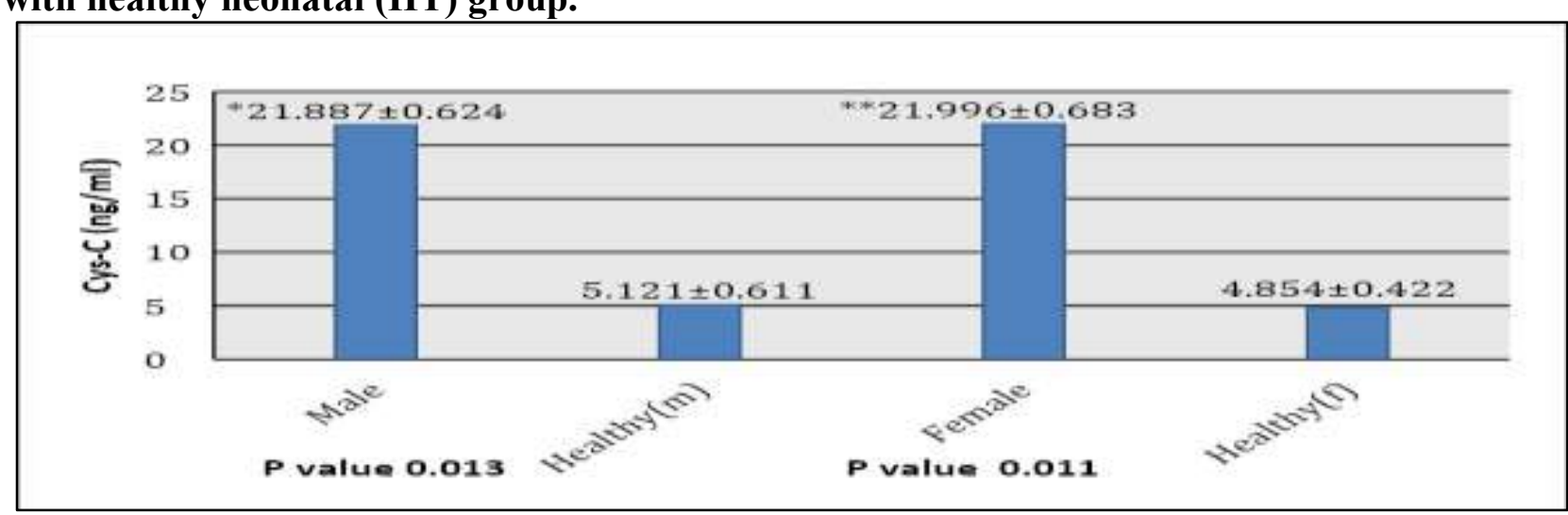

*Statistically significant differences $(\mathrm{P}<0.05)$ between male and healthy $(\mathrm{m})$.

**Statistically significant differences $(\mathrm{P}<0.05)$ between female and healthy $(\mathrm{f})$.

Figure (2):serum level of Cystatin-C in neonatal hyperbilirubinemia (male, female) patients comparison with healthy neonatal (HT) group.

\section{Correlation between Cystatin- $\mathrm{C}$ and bilirubin}

The result presented in figure (3) marked positive and significant correlation of Cys-C serum concentration with bilirubin $(r=0.9331)$. 


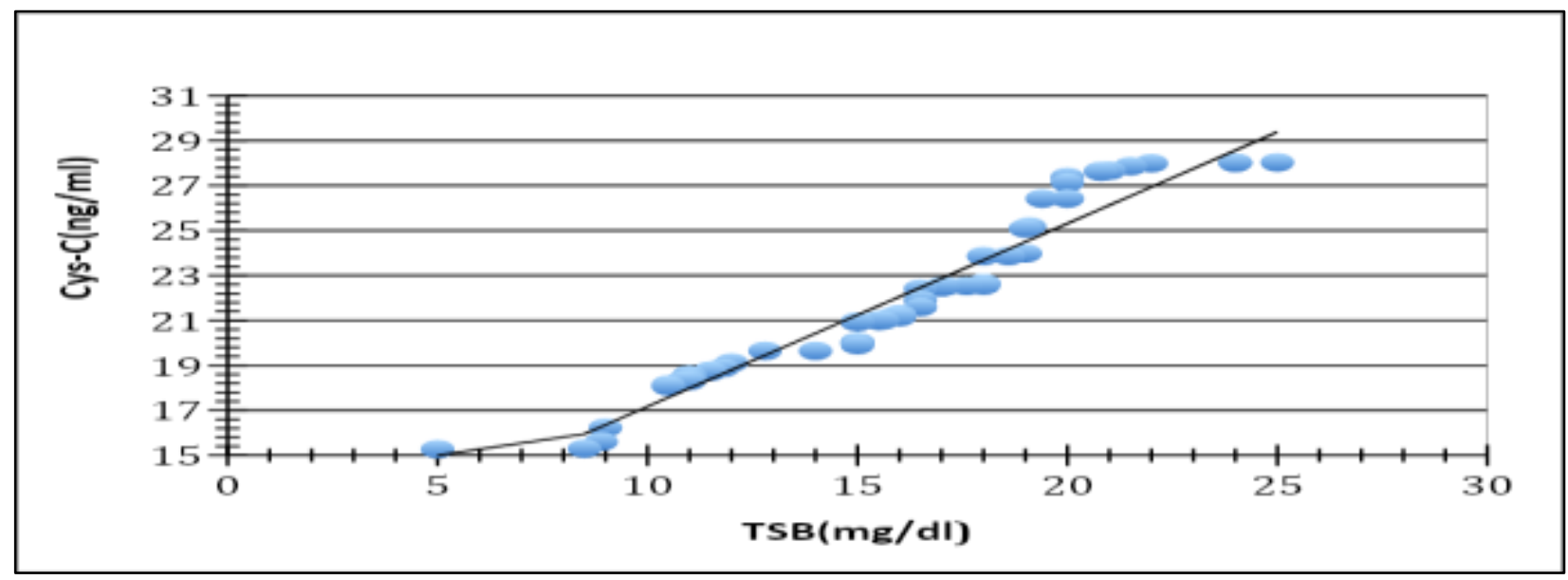

Figure (3): Correlation between cystatin-C and bilirubin in neonatal hyperbilirubinemia.

\section{DISCUSSION}

\section{Comparison among different age of groups of neonatal hyperbilirubinemia.}

The result of the current study observes significant differences $(p<0.05)$ in serum level of Cystatin-C at age (1-3)days, $(18.206 \pm 0.31 \mathrm{ng} / \mathrm{ml})$, whilst, the result of neonatal hyperbilirubinemia with age (4-6) shows significant differences $(\mathrm{p}<0.05)$ in serum level of Cys-C $(21.587 \pm 0.163 \mathrm{ng} / \mathrm{ml})$. While at age (7-9) days, Cys-C (26.005 $\pm 0.437 \mathrm{ng} / \mathrm{ml})$. The result of the current measured level of Cys$\mathrm{C}$ and they noted level of Cys-C was increased with age. While Kazuo and Akiko, (2002) documented the urinary level of Cys-C was not influenced by muscle mass or age. The result of the current study in accordance with the results of the study Zhang et al., (2014) ;Hung et al.,(2015) showed that the total serum bilirubin level (TSB) rises with age, they documented in their study, the reference intervals of total bilirubin for apparently healthy elderly should be established according to different age and sex groups.

Comparison of Cystatin- $C$ between neonatal hyperbilirubinemia patients (male, female) and control group.

The result of the current study has shown elevated in serum level of Cys-C in neonates with hyperbilirubinemia when compared with healthy neonatal (Bilirubin levels within the normal range) figure (1).

Production of Cystatin- $\mathrm{C}$ in the body is stationary process not effected by renal conditions, diet factors, and increased protein demolition. Thus, unlike creatinine, which alters with muscle mass or age (Filler et al.,2004). The relationship between Cys-C and GFR was higher among native kidney disease patients than in healthy persons (Rule et al., 2006). In the agreement with the current study Cepeda et al., (2010) has shown the high level of Cys-C to be associated with traditional cardiovascular risk factors such as diabetes, hypertension and chronic renal disease. Patients with hypertension showed significantly higher level of Cys-C as compared to those without hypertension. Cys-C may provide new ideas into the importance of the correlation between kidney disease and hypertension in subjects with presumably normal kidney function (Salgado et al.,2013).

The result of the present study shows there is no statistically significant difference between male and female as shown in Fig (2). As cystatin-C independent upon many factors one of them, is gender. There are several studies in accordance with the present study, Finney et al., (2000); Stevens et al., (2009) were considered cystatin-C not influenced by age, and body composition, gender and sweat which in the conformed with the present study.

\section{Correlation between Cystatin- $\mathrm{C}$ and bilirubin}

The correlation between cystatin-C and bilirubin that showed in figure (3) infer positively with a significant statically $(r=0.9331)$.

Plasma level of cystatin-C was suggested as a novel alternative marker for GFR (Coll et al.,2000) based on its characteristics not 
affected by a muscle mass, gender and age. Coll et al., (2000); Filler et al., (2004), proposed that in renal dysfunction increased level of cystatin$\mathrm{C}$ may be a more sensitive indicator than traditional creatinine. In neonates with bilateral kidney malformation high level of Cys-C may reflect the renal endowment low. In term neonates, the nephron mass is complete at birth. Nevertheless, neonates with congenital anomalies of kidney development of impaired kidney occur and lead to a lower nephrons number and an increased risk to lower renal function at birth (Luyckx and Brenner,2010; Bertram et al.,2011).

Hyperbilirubinemia can be defined as any blemish in the steps of bilirubin metabolism, so overproduction or impaired in uptake and conjugation causes indirect/unconjugated hyperbilirubinemia, while impaired in excretion of bilirubin result from damaged of hepatocytes or bile ducts cause direct/conjugated hyperbilirubinemia (Cui et al., 2001; Wang et al.,2003). The concentration of bilirubin in the blood is increased when hemoglobin in aging red blood cell is destroyed in patients suffer from liver disease or disorder of liver function (hepatitis and blocked bile duct). Thus, only direct or conjugated form of bilirubin is filtered by the kidneys and is secreted into the urine (urine bilirubin) (Kraingkrai et al.,2011). Therefore, from this study we conclude that the

\section{REFERENCES}

Abrahamson, M.; Olafsson, I.; Plasdottir, A.; Ulvsback, M.; Lund Wall, A.; Tensson, O. and Grubb, A., (1990). Structure and expression of the human cystatin $\mathrm{C}$ gene. Biochem J.,268(2): 287-94.

Astor, B.C.; Levey, A.S.; Stevens, L.A.; Van, L.F.; Selvin, E. and Coresh, J., (2009). Method of glomerular filtration rate estimation affects prediction of mortality risk. J Am Soc Nephrol., 20(10):2214-2222.

Bertram, JF. ; Douglas-Denton, RN. ; Diouf, B. ; Hughson, MD. and Hoy, WE. , (2011). Human nephron number: implications for health and disease. Pediatr Nephrol., 26(9): 1529-1533. excessive increase in the level cystatin- $C$ in serum is caused by a defect in glomerular filtration rate. Thus, this leads to an imbalance in the final steps of the process of excretion of bilirubin in urine, so bilirubin proportion is rising in the neonates' blood.

\section{CONCLUSIONS}

The association between TSB status and biomarkers has been demonstrated in neonatal hyperbilirubinemia. The serum level of cystatin-C alone was a best indicator of creatinine clearance than serum level of creatinine. High level of cystatin-C is involved in kidney dysfunction, initiation and progression of neonatal hyperbilirubinemia. There is a relationship between age and the high level of biomarkers as a result of severe systemic damage.

\section{ACKNOWLEDGEMENTS}

I extend my gratitude and appreciation to the staff of AL-Zahra Educational hospital in AlNajaf / Iraq for their help during the period of the work. My special gratitude to the families of babies for their cooperation with me.

Cepeda, J.; Tranche-Iparraguirre, S.; Marín-Iranzo, R.; Rodriguez, E.F.; Garcia, A.R.; Casas, J.G. and Rodriguez, E.H., (2010). Cystatin C and Cardiovascular Risk in the General Population Revista Espanola Cardiologia. Revista EDC., 63(4): 415-22.

Charlton, JR.; Portillaand, D. and Okusa, MD., (2013). A basic science view of acute kidney injury biomarkers". Nephrol Dial Transplant, 29(7): 1301-1311.

Chen, JM.; Dando, PM.; Rawlings, ND.; Brown, MA.; Young, NE.; Stevens, RA.; Hewitt, E.: Watts, C.; Barrett AJ., (1997). Cloning, isolation and characterization of mammalian legumain, an asparaginyl endopeptidase. J Biol Chem., 272(12):8090-8.

Christine, A.; Whitea Greg A.; Knoll Emilio and Poggio, D., (2010). Measuring vs estimating glomerular filtration rate in kidney 
transplantation. Transplantation Reviews, 24(1):18-27.

Coll, E. ;Botey, A. ;Alvarez, L.; Poch, E.; Quinto, L.; Saurina, A. ; Vera, M. ; Piera, C. and Darnell, A.,(2000). Serum cystatin C as a new marker for noninvasive estimation of glomerular filtration rate and as a marker for early renal impairment. Am J Kidney Dis., 36(1):29-34.

Cui, Y.; Konig, J.; Leier, I.; Buchholz, U. and Keppler, D., (2001). Hepatic uptake of bilirubin and its conjugates by the human organic anion transporter SLC21A6. J Biol Chem., 276(13): 9626-30.

Filler, G.; Bfkenkamp A.; Hofmann, W.; Le Bricon T.; Martínez-Brú, C. and Grubb, A., (2004). Cystatin $\mathrm{C}$ as a marker of GFR - history, indications, and future research. Clinical Biochemistry, 38(1):1-8.

Finney, H.; Newman, DJ. and Price CP., (2000). Adult reference ranges for serum cystatin $\mathrm{C}$, creatinine and predicted creatinine clearance. Ann Clin Biochem.,37(1):49-59.

Grubb A., (2000). Cystatin C-properties and use as diagnostic marker. Adv Clin Chem.,35:63-99.

Huang, L. ; Bao, Y. ; Xu, Z. ; Lei, X. ; Chen, Y. ;Zhang, Y. ; Zhang, J. , (2013). Neonatal bilirubin levels and childhood asthma in the US Collaborative Perinatal Project, 19591965. Am J Epidemiol. 178(12):1691-1697.

Hung, LH.; Huong, NT. and An, NTT., (2015). Jaundice in Adult In-Patients at a Tertiary General Hospital. Journal of Biosciences and Medicines,3(2):1-11.

Kaplan, M.; Hammerman C., (2002). Glucose-6phosphate dehy- drogenase deficiency: a potential source of severe neonatal hyperbilirubinaemia and kernicterus. Semin Neonatol.,7(2):121-128.

Kazuo, U.; Akiko, G., (2002). Measurement of cystatin-C and creatinine in urine. Clinica Chimica Acta., 323(1-2):121-128.

Kraingkrai, P.; Norio, T.; Kate, G.; Shoji, M. and Tadao, S., (2011). Simultaneous injection effective mixing analysis system for the determination of direct bilirubin in urinary samples. Talanta, 87(15):113-117.
Luyckx, VA.; Brenner, BM., (2010). The clinical importance of nephron mass. J Am Soc Nephrol., 21(6): 898-910

Maria, C.P. Franco; Sônia K. Nishida and Sesso, R., (2008). GFR Estimated from Cystatin C Versus Creatinine in Children Born Small for Gestational Ag. American Journal of Kidney Diseases, 51(6): 925-932.

National Institute for Health and Clinical Excellence (NIHCE), (2010). Neonatal jaundice. CG98. London: National Insititute for Health and Clinical Excellence.

Qiang, L.; Fang, J.Y.; Wang, W.P.; Liu, J.H. and Wang, K.K., (2010). Cystatin C and serum creatinine in estimating acute kidney injury of shock patients. World J Emerg Med., 1(3):185-189.

Rule, A.D.; Bergstralh, E.J.; Slezak, J.M.; Bergert, J. and Larson, T.S., (2006). Glomerular Filtration Rate Estimated by Cystatin C among Different Clinical Presentations. Kidney International, 69(2): 399-405.

Salgado, J.V.; França, A.K.; Cabral, N.A.; Lages, J.; Ribeiro, V.S.; Santos, A.M. and Salgado, B.J., (2013). Cystatin C, kidney function, and cardiovascular risk factors in primary hypertension. Revista da Associação Médica Brasileira., 59 (1): 21-27.

Shlipak, M.G.; Sarnak, M.J; Katz, R.; Fried, L. F, Seliger, S. L.; Newman, A. B.; Siscovick, D. S. and Stehman - Breen, C., (2005). Cystatin $\mathrm{C}$ and the risk of death and cardiovascular events among elderly persons. N Engl J Med., 352(20):2049-2060.

Stevens, L.A. ; Schmid, C.H. ; Greene, T. ; Li, L. ; Beck, G.J. ; Joffe, MM.; Froissart, M. ; Kusek, JW. ; Zhang, YL. ; Coresh, J. and Levey, AS. , (2009) . Factors other than glomerular filtration rate affect serum cystatin C levels. Kidney Int., 75(6):652-660.

Wang, P.; Kim, RB.; Chowdhury, JR. and Wolkoff, AW., (2003). The human organic anion transport protein SLC21A6 is not sufficient for bilirubin transport. J Biol Chem., 278(23): $20695 \mathrm{e} 9$.

Watchko, J.F.; Maisels, MJ., (2003). Jaundice in low birthweight Infants: pathobiology and outcome. Arch Dis Child Fetal Neonatal Ed. 88(6): 455-458. 
Woodgate, P.; Jardine, L.A., (2011). Neonatal jaundice. BMJ: Clinical Evidence, 09:319.

Young Infants Clinical Signs Study Group (YICSSG), (2008). Clinical signs that predict severe illness in children under age 2 months: a multicentre study. Lancet., 371 (9607):13542.
Zhang, G.M.; Xia, Y.J.; Guo, X.X.; Zhu, B.L.; Zhang, G.M. et al., (2014). Reference Intervals of Total Bilirubin, ALT, AST, and Creatinine in Healthy Elderly Chinese. Med Sci Monit., 20: 1778-1782. 